\title{
A Critical Appraisal of e-Governance Service with special reference to Rajasthan Land Records
}

\author{
K L Jawaria ${ }^{1, *}$, Vijay Singh Rathore ${ }^{2}$, K S Sharma ${ }^{3}$ \\ ${ }^{1, *}$ Researcher, Department of Computer Science \& IT, The IIS University, Jaipur-302020(India) \\ ${ }^{2}$ Director, Shree Karni College \& KISMAT, Jaipur. \\ ${ }^{3}$ Advisor, The IIS University, Jaipur - 302020 (India).
}

\begin{abstract}
Over the years, with influx of e-Governance movement in India, numerous ingenious initiatives have been conceptualized to strengthen ICT services in the country and to channelize the changes enabling technology to the last level. However, the gaps were always present and there is a dire need to have a case study on overall approach to identify and analyze the root-causes, and recommend steps for delivering seamless egovernance services in all parts of the country. It is monumentally important to have focus on establishing seamless e-governance models/modules across every nook and corner, to realize the goal of comprehensively integrated services across Government departments and service providers across their jurisdictions, preparing India for knowledge based future. The concept of reusable programs/tools/applications put together in the form of a common national repository for the App Store under e-governance, establishes the framework for products and services offered by the Government as part of the e-Governance. However, for its effective implementation there will be an essential need to offer flexibility to customize \& configure applications as per the local requirements. Also, it must offer a forum for user feedback and quality control.

Index Terms: ICT, E-Governance, GIGW, NLRMP, CLR, RoR, CSC.
\end{abstract}

\section{Introduction}

This case study aims to highlight the need for the use of ICT by governments to enhance the range as well as quality of solutions, services and offerings provided to people, civil society organizations, and other government agencies in the most suitable and convenient manner, making government processes more transparent and accountable for strengthening democracy. The rapid flow of information and service delivery in the modern world has become a norm and the concept of "anytime, anywhere" culture has emerged in the services related to the land records system.

At the basic level, all government departments should have their own websites and must follow the Guidelines for Indian Government Websites (GIGW) guidelines to the world web. Government is gradually moving towards the adoption of more sophisticated e-governance offerings, moving from information to transactions to integration and ultimately to transformations. In fact e-governance is not a linear process. Late adopters of e-governance need not start at the basic level but they can execute and improve by learning experiences of early starters.

It has been found that there is a rather peculiar correlation between barriers and adoption. Technology is not a primary barrier to e-governance, especially as government experience, organizational and political factors are more likely to affect e-governance application development, performance and adoption. Now the question is once e-governance application has been built, do citizens come forward to take advantage of the same. Once they arrive at the service centre, what do they find and what they think of as to what is there? More importantly and usually an afterthought, what about those who are not using e-governance? Why do people not use the e-governance services? How to motivate them to take advantage of e-services? The current and future research should endeavor to get answers to these questions.

\section{Project Background}

The scheme of Computerization of Land Records (CLR) was started in 1988-89. This was a 100 per cent grant-in-aid programme employed by the State Governments. The fundamental objective of CLR scheme was that landowners should get computerized copies of Records of Rights (RORs) at a reasonable price. The ultimate objective of the scheme was 'on-line management' of land records in the country. And later, The National Land Records Modernization Programme (NLRMP) was launched by the Government of India in August 2008. This programme was formulated by merging two Centrally Sponsored Schemes, i.e., Computerization of Land Records (CLR) and Strengthening of Revenue Administration \& Up-dating of Land Records (SRA \& ULR) during the year 2008-09. The activities supported under the programme include completion of computerization of the records of rights (RoRs), digitization of maps, survey/re-survey using modern technology including aerial photogrammetry, computerization of registration, training and capacity 
building of the concerned officials and functionaries, connectivity amongst the land records and registration offices and land records management centres at tehsil/taluk/circle/block level.

\subsection{Pre-Implementation Challenges}

The state economy of Rajasthan is based on agriculture. In the state, individual land holding is very small. Land records constitute vital element, both in anti-poverty strategy and for modernization. Majority of the people are under its direct control by way of their possessing even a small piece of land. Historically, Land Records Administration is under one of the oldest and traditional Government departments.

Patwari at village level maintains record of land ownership. With the traditional way of working and record storing, it has become difficult to cope with the people's demand for searching and updating of records, as the demand has increased manifold and these methods have become inadequate to cope up with the situation. Basic record of ownership details is maintained in Jamabandi. Land transaction is a regular phenomenon. The legal transformation of land takes place by mutation. Based on mutation, transactions are marked in Jamabandi where it affects the ownership. As per provisions of the Land and Revenue act, for one fourth of total villages of each tehsil, new Jamabandis are written every year by rotation, which is quite cumbersome and time consuming.

There was heterogeneity in manual records maintenance because the land records system was going the traditional way. Since they were valuable records, so no authority wanted to compromise their data not maintained in standardized form. Efforts were made to standardize the available data so that a common database design could be made. However, there was lot of resistance in converting the data to standard format. Due to lack of standardization and hand written data, it became too difficult to retrieve data from land registers. The wear and tear further had worsened it. Government had to put lot of efforts in standardizing the data without loss of the data and maintaining the legal sanctity of the same.

A number of voluminous registers were being utilized to maintain land records and it was difficult to trace if any anomalous entry was made. Already a large part of land belonging to government, reserve land, forest land, protected area was manipulated and ownership diverted to private owners by land mafia. Poor and under privileged were the worst sufferers as they had little idea about Record of Right.

Since manual and computerized records systems were working together, there was lack of responsibility and ownership in effective service delivery and as a result there was lack of trust in both the systems from citizen perspective. Also, computerization of records became informatory rather than legal documents largely, and the process of re-engineering was not as effective as was expected. Field patwari and jamabandi were more updated than computerized records. This issue came up during the survey and then it was realized that two parallel systems can work together but only till a certain period of time and one should transition to the advanced system completely after a certain period of time.

So this implies that, inspite of investing huge funds in a project since its inception, people are not being benefitted as per the objective of the programme. Reliability, accountability, availability and security are major concerns of e-governance service.

\subsection{Present e- Governance service delivery system}

Apnakhata Rajasthan is Rajasthan Government's project which works under the Revenue Department of Rajasthan Ajmer. A common man can get or view any land records copy by accesses the website http://apnakhata.raj.nic.in. Through this site Rajasthan State map is displayed as an interface page. The Rajasthan State map is comprises of 33 districts, in which a district is shown with their respective tehsils. The land-holder's entire record can now be viewed by selecting tehsil, name, Khata (account) and Khasra (serial) numbers anapnakhata official website. There are 313 tehsils in the state. Revenue records are maintained by Tehsil. A Tehsil is comprises of 4 to 6 land revenue circles whose in-charge is Inspector Land Revneue (ILR) Girdawar. Under each ILR circle number for Patwar Mandal exists, whose in- charges is Patwari. Normally a Patwar Mandal consists of number of villages.

Each village Jamabandi records is managed and maintained in Vikram Samvat for the period of four years. The system is in existence since the formation of Rajasthan State 1957. The entire records are written in Hindi. The same was converted digitally in Hindi from 1996-97 onward in phased manure.

A person has to click on desired district then further clicking on concern tehsil. It is an independent revenue records management $\&$ maintenance unit under district administration. A person has to click on first character of village name, it will show all villages name begin with selected character followed by respective Patwar Mandal, ILR and period Hence in this way a person is able to reach desired village name. Then, one can access revenue records, just key-in by khata number / khasra number. The ownership details are displayed that is known as Khate ke Nakal or copy of records of right. If one forgets his khata number then he can key-in his name detail for this a virtual key board of Hindi character is given, so that selection becomes user friendly and can get the desired land ownership details. That entire revenue records are made available in public domain so 
that anyone can see any one's records. This itself is a History in the era of land records computerization initiated by government.

As per Rajasthan Land Records Rules, the mutation i,e land ownership transfer process take place at respective Patwar Mandal and mutated processed are to be key-in by respective Patwari at Tehsil level, therefore there exist a time gap between field Jamabandi records of Patwari verses computerized records. Technically, each tehsil data is being maintained in separate database but for common citizen there is an integrated system. The records becomes legacy once the current chausal period is complete. In this Apnakhata, data is made available with multiple years chausal i.e one can track its records from 1996-97 to as of now through this application.

The services for the issuance of copy of land records is made available at multiple channels i.e Tehsil computer centre, website, authorized centres \& e-Mitra Centres in the interest of e-governance service.

\subsection{Post Implementation Observations}

- Despite having clear vision, the programme could not be completed as per the objectives laid out.

- It is surprising that despite 19- years of project implementation, government could not find the lacunae of the system and is unable to discontinue the manual system.

- Lack of ownership and leadership of program execution at grass root level as both the systems are running parallel.

- Since there was a difference between computerized copy and manual copy, so obviously end users were using manual RoR for legal purpose and computerized copy for information purposes

- It is true that the scheme is beneficial and very much required for common man but from legal point of view, it is still not valid

- The efforts were made for digital signature database but it is only available for few of the tehsils

- There is no portal to make the prescribed fee payment as per norms, i.e., it must have financial transactions base

- A reform is requried for sanctioning of mutation through Tehsildar to Tehsil database then in field Patwari Jamabandi for their day-to-day work.

- Lack of net connectivity even upto tehsil centre and requirement of redundancy of infrastructure.

\subsection{The Rationale}

\section{The 'e-Governance Service’- Impact Survey}

A well-designed program can fail when people are not involved or motivated to access services. In typical Indian environment, people still have trust on traditional system of getting works related to land records done through land record offices rather than resorting to e-governance services. However, now with the advent of education, the approach of farmers is changing. It is noteworthy to state that now the educated farmers want to get prompt, accurate and most suitable responses with the use of websites. The challenge that we face today is that most of the e-governance services are either partially implemented or are in completion phase. The process of execution is time taking and highly dependent on the discretion of officials at multiple levels of bureaucratic framework. The red tapism prevalent in the Government system makes the process too much complicated and overwhelming and takes away the farmers' interest because of the slow pace of on-ground execution. This explains why people are more comfortable with traditional and rudimentary systems rather than state-of-the-art e-services. This reasoning stands true in the field of land records management as well. In the present study survey was conducted keeping in view that despite fifteen years of project implementation, the project could not be developed to have a system oriented framework in the Rajasthan state. As stated earlier, partial implementation will never be successful. Awareness is essential and a new system takes time to establish, but it must be given sufficient amount of time to take desired shape. The duration must not be open ended. A deadline is essential to achieve tangible results. The closed ended set-up affects the mindset of officials involved in the project and pushes them to deliver what citizens need and desire.

The major components of this 'e-governance service impact survey' comprise of public awareness, post implementation observations, service analysis, ICT infrastructure issues, website application status, reasons for e-governance failure, role of better infrastructure and technological factors. Its outcome can be used for making the system effective through the feedback received from government officials, directly involved in service delivery for the citizens.

The survey data obtained from the responses of government officials and common citizens was systematically analyzed and critically examined. It would also be valuable in future research to examine citizen uptake and use of e-governance. Similarly, the information gathered from common-men, who are directly/indirectly involved in land ownership title, will strengthen the e-governance framework. 


\subsection{Survey Sampling and Approach}

The Rajasthan state was taken as sample universe for conducting this survey. In this universe, stratified sampling design is used to find the sample size. There are thirty three strata, each with respect to a district stratum. Two tehsils from each district were selected irrespective of number of tehsils in a district. Simple random sampling is used to select 10 units from each tehsil. Further, from each tehsil, a total of 10 questionnaires were filled-up, in which four questionnaires pertain to government officials who are actually involved in field data management and rest were filled up by citizens who are availing of the e-services. It was expected that this study, involving combined responses, i.e., from the service providers and from those availing of the services, will help in exploring an effective framework for citizen service delivery system. A total of 660 responses to questionnaires were taken, out of which 220 were filled up by government officials and rest 440 by citizens availing of the e-services with the help of stratified sampling procedure.

\subsection{Research Design and Pedagogy}

A questionnaire was prepared to take responses of the citizens to understand the impact of egovernance services at grass root level. Using a survey research method is considered to be an appropriate methodology to understand the awareness amongst masses and usage of e-governance services. Another questionnaire was prepared for taking responses of the Government officials involved in providing of e-services, including the technical persons, to understand shortcomings of the system and difficulties faced by them. In this study, the approach used by government officials and the benefits available to the end users were studied in detail.

\subsection{The Case Study Design}

The case study is focused on only one area of e-governance service i.e., 'Land Records' and discusses end to end solution approach for effective service delivery. Since the questionnaire was filled up by the people working on the ground level, be it government officials or the end users availing the services across various districts of Rajasthan. In the questionnaire meant for government officials, the information has been filled-up by the respective district's officials, in which these officials have been involved since inception of the project fifteen years ago, being technically aware of the background and closer to domain experts of the field. Also, the project personnel were involved in knowing the ground reality and actual impact of e-governance services. Further, the officials involved in delivering land record services are in day-to-day co-ordination with their onfield counterparts. The study has been made across all the districts of the state of Rajasthan.

\section{1 Analytics}

\section{Results and Findings}

An analysis of the responses to questionnaire was done by using statistical tools and techniques such as SPSS software \& MS Excel. It is revealed that Land Records Service is quite popular in the state and most of the citizens are aware of this e-governance service. This service is also beneficial for government departments, such as Forest, Irrigation, Panchayati Raj, Planning, Drought calculation etc. and efforts have been put-in for managing and updating records. $23 \%$ of citizens revealed that land records are not updated as per their computerized RoR and manual records, as mutation take place at field level and there is time gap in updating of records at central level. Hence, necessary measures should be taken to reduce the time gap, so that citizens could trust on the computerized data. Despite 19 years of e-governance scheme in existence, the system of issuance of copy still exists, which seems that the e-governance system is not made indispensable and trusted wholly. The citizen still has to move at field functionaries to get authenticated copy of RoR. Also digitally signed copies are made available by few tehsils, though there is no payment gateway to deposit fee online. However, an intermediary service mechanism is facilitated through e-Mitra centres. Citizens have to wait and get the copy in two trips. Therefore their requirement becomes costly due to non-availability of the payment gateway functionality. During last few years, the service delivery system has improved significantly. Also, the service area has increased from urban to rural area, where internet connectivity is made available by the service provider. There is a need for multiple channels to deliver the service so that citizens may use the service as per their convenience.

It is observed that the ICT infrastructure has to be essentially strengthened by means of Data Centre, network connectivity, reusability \& interoperability. Further, the application is also to be made simple with userfriendly interface for common man to access. The data available is informatory and offers significant help to people at large.

\subsection{Infrastructure Related Issues}

- It is observed that for large e-governance programmes, proper infrastructure is essential and it was evident from the observation that computer systems were not replaced, not even upgraded 
- There was a requirement of maintenance of systems and the hardware used, but it was observed that AMC was not even considered during the implementation.

- Over these many years, only $20 \%$ sites were renovated.

- There was lack of internet connectivity at some places and at some other places there was redundant connectivity

- However, centralized architecture was made which could be updated and accessed from various locations, but 60 tehsils were still working in standalone mode.

- There was no schedule incorporated for Capacity building and enhancing the application.

- Technology upgradation is required at least in 4-5 years, which had not taken place.

\section{3 e-Governance failure}

- Lack of trust of citizens/end users between computerized records and manual records due to difference in manual records verses computerized copy.

- Ownership has not been encapsulated in their service profile. Things have been moving slow and there has been no synergy to accelerate the program.

- Connectivity is the fastest way to reach people but due to non-availability of internet or poor connectivity, application access is an issue

- Storage of records on central server is an administrative issue but if the same was done from field then the gap of updation could have been eliminated. There must be a regulatory system that will generate a unique number and accordingly manual records should have been updated.

\subsection{Inadequate Architecture and Technology}

- Centralized architecture is required.

- It is recommended to have two servers, one at district level and other at state level.

- The state servers must have disaster recovery mechanism so that failure can be switched instantly

- Cloud computing will help in reducing the hardware cost at each location and will also take care of Disaster recovery

- $\quad$ Any up-gradation should be done centrally.

\subsection{Reduction in Cost and Time}

The cost and time required for availing services has been reduced significantly. The major reason behind this fact was fast speed of working due to computerization. The average number of trips was decreased to about 1.5 which was a very significant change. Less number of trips actually resulted in lesser cost and time for availing the services. Establishment of service access points near to the location of citizens also reduces the cost and time required. Earlier the citizen/end user used to spend 3-5 hours or a whole day for a small work but now that time has reduced to 15-20 minutes after implementation of e-governance project.

One of the major findings of this study is that the satisfaction level of e-Governance application users is very high. The cost of availing services has decreased significantly and so is the time and effort required for availing services. Almost 95 percent of the government officials believe that e-governance initiatives have benefitted the users / citizens.

\subsection{Last Mile Connectivity Problems}

In small districts, availability of electricity and internet connectivity is very poor; hence online services are not available in rural areas. Due to low computer literacy and no computer facilities in rural areas, citizens could not use e-Governance services from their homes. This situation makes apparent the need for Common Service Centers scheme (CSC), the most important e-Governance service in rural areas. The most important egovernance services in such districts are: CSC (Billing, Digital Certificates), Land Record Computerization, Esugam (Single window for various purposes) etc.

\subsection{Administration Attitude}

Administration is trying hard to cover the gap between govt. efforts and citizens satisfaction. Hence, all the information about facilities in villages is updated on E-Gram portals. The administration is running awareness programs like 'Gram Sabhas', 'Preraks', 'Jan Sunavai' both via electronic and print media.

Moreover, there is high acceptance in citizens with respect to realization of benefits of the e-government initiatives and all the e-governance initiatives of GoI and GoR have been implemented. 


\section{Conclusion and Way Forward:}

In essence, the argument in favor of e-governance services is that by accessing information from the government through technology, the lives of citizens can be improved to a great extent. Digital India Program will be truly successful when its results are comparable with prevailing e-governance programs of developed countries.

In this world of digitalization, expectations of citizens are also high. e-Governance is the key tool to fulfill those expectations. Each day technology upgrades itself, which also increases the expectations in a qualitative way. This creates continuous challenges and opportunities for the government.

Respondents with diminutive information about the projects are also un-sure about the potential benefits of the projects. This indicates that current awareness creation process (if any, in existence) has some flaws in creating true awareness. Whereas, a large number of respondents who had no idea about e-governance, many of them expressed very optimistic opinion, after briefing sessions conducted by the investigator.

The researcher has observed impact of e-Governance on citizens and government employees. eGovernance projects have helped in better administration and helped to promote greater transparency and accountability and provides a citizen friendly environment. These projects also help in better service delivery. It is not an easy task to eliminate corruption and it requires extraordinary efforts. e-Governance has shown promise in this regard, and in many instances it has delivered by eliminating or mitigating corruption in public services delivery.

Active public participation is required to make e-Governance successful. Negative perception of citizens about service delivery is a major challenge before the government. But citizens are very curious and adoptive, so if they will be cognized then it will be more fruitful.

Finally, it is observed that for successful implementation of an e-governance project, officials require tenure of at least 4-5 years, so that such large projects can be understood deeply and have involvement at micro level processes. The system is improving and people are being facilitated with various e-governance services.

\section{References}

[1]. Gupta, Vivek (2003) “e-Government: The New Revolution”, The ICFAI University Press, Hyderabad, India

[2]. Kaur, J. and Rathor, V. S. (2012) "Importance of ICT and E-Governance Security in Punjab", Global Jouranl of Computer Science and Technology, Vol. 12, issue 2

[3]. Malik, P., Priyanka, D., \&Verma, P. ( 2014). "Challenges and Future Prospects for E-Governace in India”, International Journal of Science, Engineering and Technology Research, volume 3, issue 7 , 1964-1972

[4]. Mittal, P. and Kaur, A. (2013), "E-Governance: A Challenge for India", International Journal of Advanced Research in Computer Engineering \& Technology (IJARCET), March 2013, 2 (3): 1196-1199.

[5]. Kalsi, N.S., Kiran, R., \& Vaidya, S.C.,(2009), “ Effective e-Governance for Good Governance in India”, International Review of Business Research Papers, 5(1), pp. 212-229.

[6]. Dr. Pardeep Mittal, Amandeep Kaur (2013), " E-Governance - A challenge for India", International Journal of Advanced Research in Computer Engineering \& Technology (IJARCET), Volume 2, Issue 3, March 2013.

[7]. Nripendra P. Rana, Yogesh K. Dwivedi and Michael D. Williams (2013), "A meta-analysis of existing research on citizen adoption of e-government:” June 2015, Volume 17, Issue 3, pp 547-563.

[8]. www.Rajasthan.gov.in, Government, Website of Govt. of Rajasthan

[9]. www.nic.gov.in, www.deity.gov.in Department of Information Technology, Ministry of communications and Information Technology, Government of India

[10]. www.iimahd.ernet.in Indian Institute of Management Ahmedaba, http://apnakhata.nic.in,http://dolr.nic.in

[11]. Shailendra C. ,Jain Palvia1* and Sushil S. Sharma2 (2007) "E-Government and E-Governance: Definitions/Domain Framework and Status around the World:."

[12]. D N Gupta (2008) "E Governance A Comprehensive Framework :.”,

[13]. Electronic Governance: (2013)

[14]. Driss Kettani and Bernard Moulin "E-Governance for Good Governance in Developing Countries, Empirical Evidence from Project" May 2014, 298 Pages.

[15]. Gregory G. Curtin, Michael Sommer, Veronika Vis-Somme,2003.

[16]. Prabhu, CSR (2004) "E-Governance: Concepts and Cases Studies"

[17]. Lemuria Carter1 and France Bélanger2, (2005), The utilization of e-government services: citizen trust, innovation and acceptance factors*:, Volume 15, Issue 1, pages 5-25, January 2005. 